\title{
Out of the dissection room. An experience of outdoor practical sessions for animal anatomy education
}

\author{
Pere M. Parés-Casanova \\ Department of Animal Production, University of Lleida, Catalonia, Spain
}

\begin{abstract}
Practical exercises are an essential component of anatomy education, so anatomy sessions including dissection are essential for animal anatomy courses. In Spain there are not difficulties in obtaining farm animal corpses for educational purposes (although some sanitary laws restrict it in certain cases) neither in general ethical constraints. From 2009 we have been doing outdoor animal dissection for 1st level students of the "Animal Health and Science" degree course of the University of Lleida in Catalunya (Spain) in an industrial corpse destruction plant near the university. There, students practice cow dissection in order to observe simple anatomical structures, such as superficial muscles and bony points, under "field" conditions. We think that these kinds of practical lessons are a cheap and realistic educational model and clearly superior to the classical dissection performed with fixed corpses, even to those done with fresh corpses but under laboratory conditions. In this practice we found educational and technical advantages are more numerous than disadvantages, which are listed in this article.
\end{abstract}

Key words: competence; education; standards; teaching methods; undergraduate

Anatomy 2012-2013;6-7:23-28, (c) 2012-2013 TSACA

\section{Introduction}

Anatomy is one of the oldest basic medical sciences. The first anatomical descriptions were recorded on papyrus between 5000 and $3000 \mathrm{BC}$, being formally studied for the first time in Egypt about 500 BC. The teaching of anatomy has been administered in the same way since the time of its initiation as a science: corpse dissection. Some newly introduced alternative methodologies have been well accepted by students and thus learning has became more effective ${ }^{[1,2]}$ although are the patterns of teacher behavior and the teaching methods the main forces which have little to do with scientific knowledge of learning. ${ }^{[3]}$

Tavares and Alarcao ${ }^{[4]}$ consider that in the traditional paradigm of education, higher education teachers teach, transmit and explain to students the regular and available science. The emphasis is on the teacher, knowledge and its acquisition. But according to Luckesi, ${ }^{[5]}$ the reception of knowledge is not sufficient for the student to develop the necessary skills and habits, and exercising of this knowledge is required. Moreover, in the post-modern paradigm, the student must be the builder of his/her own knowledge, and less teaching and more learning is recommended. Brzezinski ${ }^{[6]}$ considers that within this new process, it is no longer possible to separate teaching from learning, one cannot exist without the other. Thus, the teaching of anatomy through the practical study of parts provides an important mechanism for learning.

Recent developments in Animal Health and Science curricula have led to marked changes in the teaching of gross anatomy. This change has involved decreasing curricular student contact time and the use of new methods for anatomical teaching. ${ }^{[7]}$ Some "modern" anatomists have welcomed the arrival of these novel method. ${ }^{[7]}$ Therefore, didactic lectures and traditional anatomy practical lessons including dissections of corpses have been enriched by a multiple range of special study modules, problem-based workshops, computers, plastic mod- 
els, and other teaching tools. We think that a major reason for the emergence of these alternative methods used in animal anatomy education might be a certain "commodity" for teachers, as well as the apparent prestige that normally these tools have in the professor curriculum.

\section{Fixed corpses for Education Purposes}

It is commonly accepted that corpses are an essential part of the medical education, and the student-corpse encounter is of paramount importance in anatomy education, even in Animal Health and Science graduates. The number of corpses dissected by each student is an important criterion of the quality of anatomy education. Although in Spain there are not difficulties in obtaining farm animal corpses (although some sanitary laws restrict it in certain cases), normally cadavers are fixed with formaldehyde, and utilised for a long time. However, corpses that are fixed using formaldehyde tend to be hardened and discoloured. ${ }^{[8]}$ In addition, this solvent has various undesired toxic properties ${ }^{[9-11]}$

Formaldehyde has adverse effects like irritation, allergy, toxicity, mutagenesis, and carcinogenesis. ${ }^{[9,10]}$ Formaldehyde also may cause cellular damage in the prefrontal cortex ${ }^{[11]}$ and alter zinc, copper, and iron levels in the cerebral cortex and testes ${ }^{[10]}$ and is also expensive.

Phenoxyethanol is another preservative product used in the dissection laboratory, ${ }^{[12]}$ but it can cause contact dermatitis ${ }^{[13]}$ and is also a reproductive toxin. ${ }^{[14]}$ Also, in general, chemical conservated corpses can look unrealistic and lead to apathy among students. Thiel's embalming technique ${ }^{[15]}$ could be an alternative technique, but it seems that no experience has been done with animal corpses.

In this study, we present our experience to do large farm animal dissection under non-laboratory conditions, in order to minimise expenses and provide students training by working under a real environment. There is no substitute for experience. This kind of practical lesson may be an alternative, convenient and ancillary method for animal anatomy practical lessons.

\section{Fresh Corpses Dissection}

From 2009 a cow dissection is directed to 1st level students of the "Animal Health and Science" students of the University of Lleida in Catalunya (Spain). Practice is performed in an industrial corpse destruction plant SERECA-BIO, which is located in a little village about $25 \mathrm{~km}$ from the university. In order to avoid disjointed and unpredictable experience, the students are previously (1 or 2 weeks before) theoretically introduced to basic personal protection measures and learning objectives by the professor, and a description of the industrial corpse destruction process that is held in that plant by a factory responsible. Four practical lessons (15 students for each practical lesson) are performed each first semester (60 students per course). The group is subdivided in groups of five per animal (3 cows per practical lesson). The same instructor supervises the three groups simultaneously. Dissections are carried out within the first 24-48 hours following the death, to eliminate the possibility of using corpses that are putrefied (although it depends on environmental temperature).

The general purpose of the practice is to observe simple anatomical structures, such as vascular, muscular and lymphatic superficial structures, in near-real states (Fig. 1). The main focus is the structure of the locomotive system. At the same time, the practice enables students to obtain good habits, such as working in team, supporting a certain discomfortability (sight, odours, cold, etc.), and respecting the needed security procedures.

Practice starts at 7 AM. Three dead cows (sometimes a bull) lie in lateral recumbency on floor. After a brief reminder of security aspects and procedure method to the group altogether, they start to practice the dissection divided into subgroups. As said above, each 5 students have their "own" cow. Body regions and directional terms are projected on the corpse. Great importance is given to the terms related to limb planes (median and sagittal, palmar and plantar, fibular and ulnar, solar and volar, etc.). In order to have a topographical-clinical view, palpable bony structures of the thorax and back (ribs, spinous processes etc.), and limbs (olecranon and calcaneal tubers, pelvic tuberosities, basipodiums etc.) are located, as well as superficial lymph nodes (mandibular, parotid, lateral retropharyngeal, prescapular, subiliac etc.). Examination of the udder (superficial inguinal lymph node, vascularisation etc.) is also done. Superficial layers of the trunk (trapezius, broadest muscle of back, serrate, deltoid, muscles of elbow joint, obliques, rump musculature etc.) and lateral muscles of the limbs are the main interest of this practical lesson, and students may dissect them in order to identify their origin and insertion points. Corpses are not opened in classical forensic autopsies, so cuts and separation of planes are directed to the desired structures in a coarser manner than in a necropsy. Moreover, this is their first semester of the course and students have had no previous training on pathology or necropsy techniques. Brachial plexus is localised (shoulder joint is disarticulated). Clinically interesting vessels (jugular, abdominal subcutaneous and lateral saphenous veins, etc.) are also presented. Finally, 
a muscular stratigraphy of the middle abdominal region is done.

The anatomical dissection is a long process (about 3 hours) that allows the student to become engaged with the superficial cow anatomy. The main focus is the structure of the locomotive system (Table 1). As said, students have not previously performed any animal dissection so the practical lesson is slowed down to allow the students to work calmly. In addition, at the end of the dissection, the students can revise their observations before the corpses were discharged and destroyed. Sometimes (depending on the interest of students) some observational features, such as estimation of age by teeth, foetal chronology (if pregnant) or simple pathological anomalies (mastitis, damaged pelvis, uterine prolapse, accessory teats etc.) can be described at the end of the lesson.

Figure 1. The general purpose of the practice is to observe simple anatomical structures, such as vascular, muscular and lymphatic superficial structures in near-real state. At the same time, the practise enables students to obtain good habits and respecting the needed security procedures (photo: Parés-Casanova).

\section{Advantages}

We observe many advantages in the outdoor fresh anatomic dissections compared with formalin fixed corpses or fresh corpses studied in the laboratory, some of which are as follows:

- Formalin fixed corpses harden and discolour, so they are unrealistic, and barely have an unpleasant odour, so a possible lack of interest is possible. Fresh corpses for dissection in anatomy courses are more realistic in colour and texture even though they present pathological changes or an incipient autolysis. If fresh, corpses have the corresponding "normal" corpse smell.

- Danger and high expense in using chemical fixer is avoided.

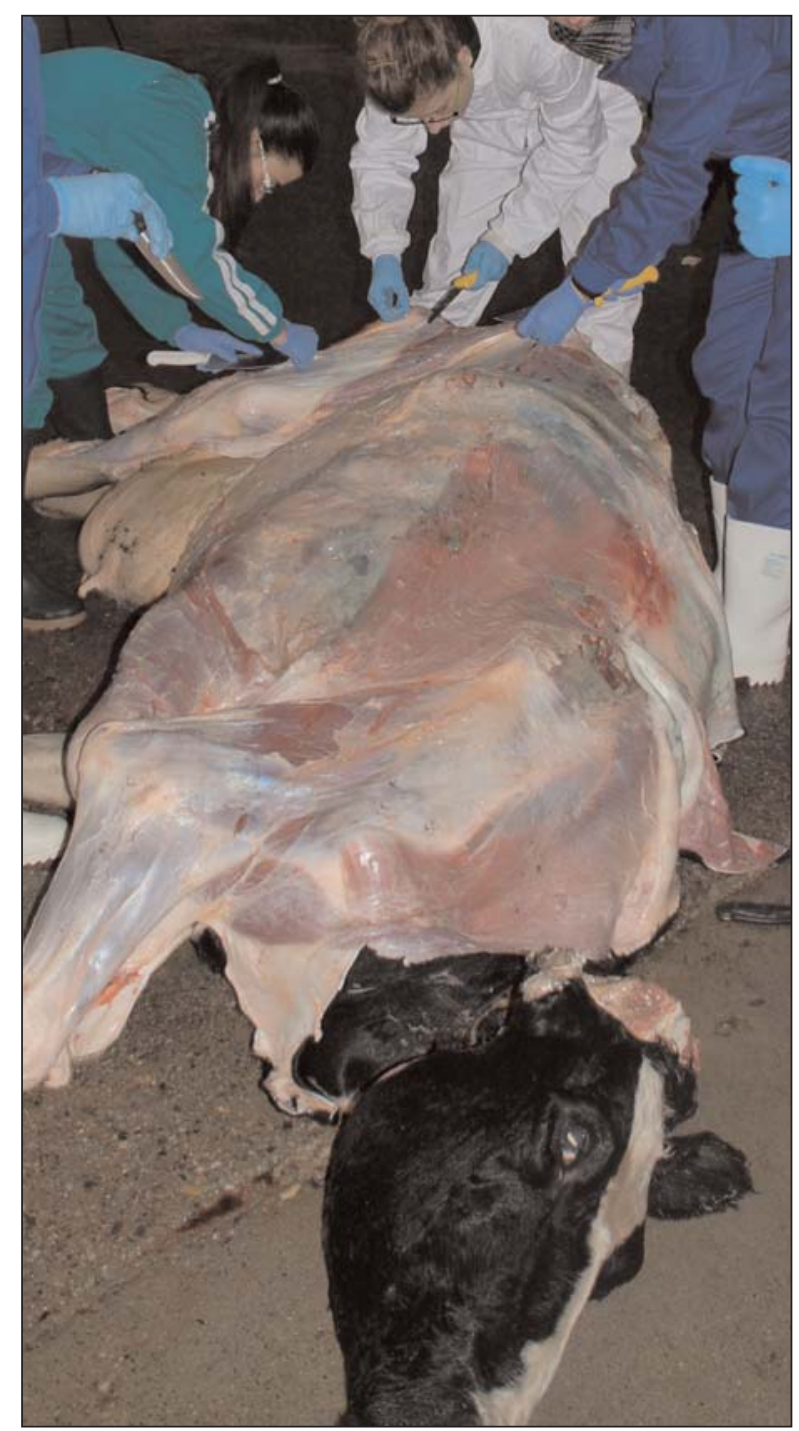


Table 1

Main focus is the structure of the practice

\section{Some directional terms and planes of the animal body}

a. Directional terms

i. Dorsal - ventral

ii. Cranial-caudal

iii. Rostral - nuchal

iv. Medial- lateral

v. Proximal - distal

vi. Palmar - plantar

vii. Axial - abaxial

viii. Solar - volar

b. Virtual planes (a surface, real or imaginary, along which any two points can be connected by a straight line)

ix. Median - paramedian

x. Sagittal - parasagittal

xi. Dorsal - transverse

2. Some bony palpable structures and landmarks (and an attempt to palpate all of them)

i. Jugular groove

ii. Ribs

iii. Greater tubercle of humerus, deltoid tuberosity, olecranon tuber

iv. Subcutaneous smooth surface of the radius and carpal bones; accessory carpal bone; metacarpal bones

v. Coxal, sacral and ischial tubers; greater trochanter of the femur

vi. Patella with its ligaments

vii. Subcutaneous smooth surface of the tibia and tarsal bones; calcaneal tuber and talus

viii. Common calcaneal tendon ("Achilles' tendon") (gluteobiceps m.+semitendnosus m.+gastrocnemius m.+ superficial digital m.)

\section{Superficial vessels}

a. Lymph nodes:

i. Of the head: parotid, mandibular and superficial retropharyngeal lymph centres

ii. Of the shoulder girdle: superficial cervical lymph centre, axillary (deep!) I.c.

iii. Of the udder: superficial inguinal I.n. ("mammary I.n.")

iv. Of the abdomen: prefemoral I.c.

v. Of the pelvic limb: popliteal (deep!) I.c.

b. Veins:

i. Of the shoulder girdle: external jugular v. (the 1st choice for blood sampling and IV injection in most animals), cephalic v. (the most popular choice for IV injection in dogs and cats; palpated by exerting pressure over the elbow)

ii. Of the abdomen: superficial cranial and caudal epigastric veins (SC abdominal v.; it enters the deep layers on the 8th IS ("milk well") to meet with the internal thoracic $v$.

iii. Of the pelvic limb: lateral saphenous v.

c. Arteries:

i. Of the head: facial a. (pulse palpation in the horse), facial a., common carotid a. and transverse facial a. (arterial blood sampling)

ii. Of the trunk: axillary a. (winding the cranial border of the 1st rib) (for arterial blood sampling), brachial a. (for pulse palpation), palmar medial digital a. (for digital pulse)

iii. Of the pelvic limb: femoral a. (for pulse in dog and cat), dorsal metatarsal artery (for arterial blood sampling)

4. Superficial muscles (see and feel their position and attachments and their action on the skeleton!)

a. Of the head: orbital muscle of mouth, buccinators, mylohyoid, masseter, medial pterygoid

b. Of the shoulder girdle: sternomandibular m., brachiocephalic $\mathrm{m}$. (with the edge of a fibrous plate, on which the vestigial clavicle is connected), omotransverse $\mathrm{m}$., trapezius $\mathrm{m}$. , rhomboid $\mathrm{m}$. , broadest muscle of back

c. Muscles of elbow joint:

a. Cranial: biceps brachii $m$. brachial $m$.

b. Caudal: triceps brachii, the tensor fasciae antebrachii, and the anconeus. By far the largest of these muscles is the triceps (a remember that in the dog consists of 4 heads instead of the usual 3), tensor $m$. of the antebrachial fascia

c. Extensors and flexors of digital joints: common and lateral digital extensor mm, superficial and deep digital flexor mm

d. Of the thoracic wall: dorsal serrate (cranial and caudal portions)

e. Of the abdominal wall: cutaneous $\mathrm{m}$., external and internal obliques $\mathrm{mm}$, transverse abdominal $\mathrm{m}$., straight abdominal $\mathrm{m}$. Linea alba and yellow abdominal tunice.

f. Of the pelvic limb:

i. Lateral aspect: gluteal m. (middle, deep, accessory), tensor de la fascia lata, gluteobiceps m. (femoral biceps m.+superficial gluteal m.), semitendnosus m., gastrocnemius $m$. (2 heads), semimembranosus $m$.

ii. Medial aspect: sartorius m., gracilis m., quadriceps m. (lateral, medial and intermediate vastus, and straight m. of thigh)

iii. Flexors of the tarsus: cranial tibial $m$., third fibular $m$., long fibular $m$.

iv. Extensors of the digits: long digital ext. m. (two bellies; ancient "common digital ext. m."; 2 terminal tendons, lateral digital ext. m.

v. Flexors of the digits: superficial and deep digital $\mathrm{mm}$, manica flexoria. 
- Large ungulates such cows and horses are difficult to acquire and prepare in the laboratory, hence students habitually do not dissect these species in their anatomy courses.

- Because dissected animals are not sacrificed, it should not demand any legal agreement, or cause ethical problems. Moreover, these animal are not used for anything else, as petfood (corpses are simply destroyed).

- No consent from the farmer is necessary.

- Dissection is performed in relatively uncomfortable conditions (cold, bad sight, odours, early in the morning etc.) so students learn to work in a harder (but more realistic and evidently affordable) environment.

- In many corpses, the body may present gross lesions (as the cause of death or not), so simple pathological change observations (fractures, bleedings, abscesses, lymphatic reactions etc.) can be introduced.

- Practice has a low cost, as no sampling and destruction of corpses by the university services are necessary. Only transportation raises a little cost, but it is assumed individually by students.

- No time is spent in preparing corpses.

- Some human values -such as physical effort and team work- are acquired by students.

\section{... But Also Some Negative Aspects}

But, honestly, some negative aspects of dissections of fresh corpses could be observed as follows:

- There are some biological hazards in using fresh materials, such as infectious diseases (brucellosis, tuberculosis, etc). The students must also be well trained in the use of protective garments (gloves, waterproof boots, overalls). Although these protective garments may make the learning process more difficult for anatomy students, the garments eliminate the biological risks. Moreover, it is the equipment they will wear in a future "professional" work in necropsies.

- Some physical risks also exist, such as accidental cutting with knives and slips (chances are higher because of awkward setting).

- This practical lesson should be performed more than once in order to allow students to gain meaningful information from what they see. Students attending a single session are frequently "saturated" by their first glance of dead animals. In our case, limited practice hours do not allow repeat of this practice.

- Corpses are not opened in classical forensic autopsies. This anatomical dissection process is shallower and coarser than a necropsy, and it must be clearly stated to students.

\section{Conclusion}

We suggest that anatomical practices should be, whenever possible, from "fresh" animal bodies a gold standard, in spite of the disadvantages enumerated above. Although anatomy images and plastic models can be accurate in explaining anatomy, real corpse dissections more adequately represent true animal anatomy. We think that these kind of practical lessons are an attractive supplementary educational (and not just curricular) model and believe that further practical lessons of this kind could lead to more consistent learning, and also in other future areas such as pathology and microbiology. It can not replace current teaching but should be added to what is currently done.

In conclusion, although we support the idea that cadaver dissection performed in the laboratory should be continued in anatomy practical lessons, we propose that in the event of it being possible, outdoor dissection of fresh cadavers is an attractive supplementary educational model, in spite of the disadvantages enumerated above. Hence, students can recognise tissues and organ systems better during these practical sessions, the knowledge of which will be essential in their future careers. Studies to investigate if these students' anatomical skills are better then those of other students who have not done this practical could be of great interest.

Universities are independent institutions devoted to education and research, and normally each centre can determine its method of instruction. New instruction methods must then be considered and adopted if possible.

\section{Acknowledgements}

My gratitude to Luís Sastre and Jordi Planas, of the technical advisory board for the company where practices are done.

\section{References}

1. Aversi-Ferreira TA, Monteiro CA, Maia FA, Guimarães APR, Cruz MA. Neurophysiology study associated with three-dimensional models constructed during the learning. Biosci J Uberlândia 2008;24:98-103.

2. Freitas LAM, Barroso HFD, Rodrigues HG, Aversi-Ferreira TA. Construction of embryonic models with recycled material for didactic using. Biosci J Uberlândia 2008;24:91-7. 
3. Naftulin DH, Ware JE, Donnelly FA. The doctor Fox lecture: a paradigm of educational seduction. J Med Educ 1993;48:630-5.

4. Tavares J, Alarcao I. Paradigmas de formacao e investigacao no ensino superior para o terceiro milenio. In: Alarcão I, editor. Escola reflexiva e nova racionalidade. Porto Alegre-RS: Artmed; 2001.

5. Luckesi CC. Procedimentos de encino. In: Filosofia da educação. Sao Paulo-SP: Cortez; 1999.

6. Brzezinsk I. Qualidade na graduacao. Educativa 2005;8:321-8.

7. Patel KM, Moxham BJ. Attitudes of professional anatomists to curricular change. Clin Anat 2006;19:132-41.

8. Küçüker H, Özen OA, Songur A, Baş O, Demirel R. Should forensic autopsies be a source for medical education? A preliminary study. Teach Learn Med 2008;20:22-5.

9. Songur A, Akpolat N, Kuş İ, Özen OA, Zararsız İ, Sarsılmaz M. The effects of the inhaled formaldehyde during the early postnatal period in the hippocampus of rats: a morphological and immunohistochemical study. Neurosci Res Comm 2003;33:168-8.
10. Özen OA, Yaman M, Sarsılmaz M, Songur A, Kuş İ. Testicular zinc, copper and iron concentrations in male rats exposed to subacute and subchronic formaldehyde gas inhalation. J Trace Elem Med Biol 2002;16:119-2.

11. Whitehead MC, Savoia MC. Evaluation of methods to reduce formaldehyde levels of cadavers in the dissection laboratory. Clin Anat 2008;21:75-81.

12. Wineski LE, English AW. Phenoxyethanol as a nontoxic preservative in the dissection laboratory. Acta Anat (Basel) 1989;136:155-8.

13. Lujan D, Hernandez-Machin B, Peñate Y, Borrego L. Contact urticaria due to phenoxyethanol in an aftershave. Dermatitis 2009;20:10.

14. Hardin BD. Reproductive toxicity of the glycol ethers. Toxicology 1983;27:91-102.

15. Benkhadra M, Gérard J, Genelot D, et al. Is Thiel's embalming method widely known? A world survey about its use. Surg Radiol Anat 2011;33:359-63.

Correspondence to: Dr. Pere M. Parés-Casanova Department of Animal Production, University of Lleida, Alcalde Rovira Roure, 191 (25198 Lleida).

Catalonia, Spain

Phone: +34 973706460

e-mail: peremiquelp@prodan.udl.cat

Conflict of interest statement: No conflicts declared. 